Research Article

\title{
Evolutionary Game Analysis of the Innovation Behavior of High-Tech Enterprises with Government Participation
}

\author{
Chen Gong, ${ }^{1}$ Jian Liu $\mathbb{D}^{2}{ }^{2}$ and Jinping Chang ${ }^{3}$ \\ ${ }^{1}$ College of Economics and Management, Qiqihar University, Qiqihar, Heilongjiang 161006, China \\ ${ }^{2}$ College of Art and Design, Beijing University of Technology, Beijing 100123, China \\ ${ }^{3}$ College of Management, Beijing Union University, Beijing 100101, China \\ Correspondence should be addressed to Jian Liu; ljym@bjut.edu.cn
}

Received 1 March 2021; Accepted 12 August 2021; Published 9 September 2021

Academic Editor: Arunava Majumder

Copyright ( $\odot 2021$ Chen Gong et al. This is an open access article distributed under the Creative Commons Attribution License, which permits unrestricted use, distribution, and reproduction in any medium, provided the original work is properly cited.

\begin{abstract}
High-tech enterprises, as the key subjects that can stimulate innovation vitality and promote innovation-driven development strategies in China, require government guidance for their innovative activities. However, the existing research has not answered the issue of how the government behavior activates the innovation ability of high-tech enterprises and what is the internal mechanism. As such, this paper takes government participation in high-tech enterprises as its research object, constructs an evolutionary game model of government participation in enterprise innovation, analyzes the internal mechanism of improvements to high-tech enterprises' innovation ability under government tax and fee policy incentives and regulatory measures, and uses MATLAB numerical simulation to verify the results. The research shows that (1) increasing the general corporate income tax rate and reducing the high-tech corporate income tax rate can promote the transformation of general enterprises into hightech enterprises and encourage enterprises to engage in scientific and technological innovation activities. However, when the hightech corporate income tax rate is lower than 0.1, the marginal effect will be reduced. (2) Increasing the deduction coefficient and amortization coefficient can make high-tech enterprises more motivated to participate in innovation activities and thus render enterprise innovation more lucrative. (3) Increasing administrative penalties from regulatory authorities can promote the development of innovative activities in high-tech enterprises, but their intensity must be controlled within a reasonable range. The presented results have reference value for the adjustment of tax and fee policies among high-tech enterprises.
\end{abstract}

\section{Introduction}

In the context of the new normal of economic development, to further transform the structure of economic development and find new forms of kinetic energy, China has implemented an innovation-driven development strategy to encourage innovation and entrepreneurship in its population. Such innovation activities are mainly pursued by enterprises. In particular, high-tech enterprises are the key players involved in stimulating China's innovation vitality and promoting innovation-driven development strategies. At the same time, innovation activities need to be guided by the government in the midst of highly complex modern technology and uncertain trends of economic development. With government cooperation, enterprises and government play the most critical role in China's implementation of innovationdriven development strategies. Exploring the internal mechanisms of the government's influence on the innovation capabilities of enterprises is essential for the government to improve its guidance and the innovation capabilities of high-tech enterprises.

As an important means for the government to encourage enterprises to engage in scientific and technological innovation activities, tax and fee policies can provide support and guarantees for the innovation of hightech enterprises. At present, China is vigorously cultivating high-tech enterprises, and through the recognition of hightech enterprise qualifications, it has given them considerable preferential treatment under taxation and research and development policies. This has involved enhanced monitoring of management in high-tech enterprises in 
various regions and putting forward rectification opinions and correcting them within a time limit for identified agencies presenting problems. When such problems are serious, the companies are notified and reprimanded. Within this process, high-tech enterprises act as subjects of innovation activities, while the government acts as a subject of incentives and supervision. Before launching an innovative activity, a high-tech enterprise will not only consider the input and output of the activity but also whether the government will adopt preferential tax policies and administrative supervision measures and the relevant behavioral decisions of the government. At the same time, the government will consider means to adjust tax and fee policies and regulatory measures to maximize the innovation capabilities of enterprises and maximize the benefits to society. Both parties continue to adjust their behavior strategies through information acquisition and experiential learning until they reach an equilibrium state. This process essentially involves a game of interest between high-tech enterprises and the government.

Consequently, the motivations of this paper are summarized as follows: how to clearly describe the behavior of government and enterprise? how to examine the game behavior process between them? and what kind of behavior is most conducive to enterprise innovation and maximization of social benefits? To respond to these, this paper introduces the evolutionary game theory to model the behavior of mutual influence between government and high-tech enterprises and analyze the evolution process and equilibrium point of the game behavior between them. The main contributions of the paper are as follows:

(1) To construct the evolutionary game model of analyzing the behavior of mutual influence between government and high-tech enterprises on innovation activity.

(2) To examine the game process of their behavior by the dynamic equation copying, thus understanding the change path of interaction behavior between enterprises and government.

(3) To solve the equilibrium point of the evolutionary game model based on the Pareto principle, so as to determine the best behavior strategy that is beneficial to both enterprises and government.

The rest of this article is organized as follows: Section 2 conducts the literature review, including the research on the evolutionary game and the impact of the government's tax policy on the innovation of high-tech enterprises. Section 3 presents the relevant theoretical research basis, puts forward basic theoretical hypotheses, and constructs an evolutionary game model of government participation in enterprise innovation. Section 4 focuses on the analysis of influencing factors. MATLAB software is used to simulate and explore the evolution of the studied system with numerical changes in the main parameters. Section 5 uses evolutionary game theory and MATLAB numerical simulation to analyze the internal mechanisms and marginal effects of high-tech enterprises' innovation capabilities under government tax and fee policy incentives and regulatory measures. Section 6 summarizes the conclusion.

\section{Literature Review}

2.1. Research on Evolutionary Game. Maynard Smith and Price explained the limited conflict between animals with game theory and evolutionary game theory in order to open up a new field. Assarzadegan et al. [1] explored for the first time a supply chain consisting of one National Brand (NB) manufacturer and a population of retailers under two scenarios. In the first, each retailer sells NB and chooses either to introduce an Economy Private Label or not. In the second scenario, each retailer chooses either to introduce a Premium Private Label or not. To solve the problem, an evolutionary game is introduced and the retailers' behavior is analyzed. Using two numerical examples, parametric analysis and managerial insights are also provided. Shi et al. [2] explored the behaviors of the diffusion system regarding low-carbon technologies, this study builds an agent-based model to simulate enterprises' reactions to multiple policy interventions aimed at spurring low-carbon technology diffusion. The model reveals a dilemma of policy interventions: intuitively, carbon taxes, asymmetric penalties, and subsidies can improve the diffusion. Tian et al. [3] proposed to consider dynamical and diversity attacking strategies in the simulation of reputation management scheme evaluation. They applied evolutionary game theory to model the evolution process of malicious users' attacking strategies and discussed the methodology of the evaluation simulations. Chen and $\mathrm{Hu}$ [4] believed that the evolutionary game theory is applied to examine the behavioral strategies of the manufacturers in response to various combinations of carbon taxes and subsidies considering that the manufactured products have no distinctly low-carbon characteristics. Kang et al. [5] explored the stable strategies analysis based on the utility of Z-number in the evolutionary games which is proposed, which can simulate the procedure of human's competition and cooperation more authentically and more flexibly. Zhang et al. [6] reviewed and analyzed the evolutionary trajectories of the government, contractors, and investors by establishing evolutionary game models under quality assurance and revenue-sharing contracts that stipulate punishments and rewards. Yu and Rehman Khan [7] explored COVID-19 and the income gap between rural areas and urban areas; they designed a financing system for GAPSC with agricultural product suppliers as financiers and urban residents as investors. Simultaneously, they built an evolutionary game model based on the relationship between agricultural product suppliers and urban residents in the financing system. $\mathrm{Xu}$ et al. [8] explored a three-population model of suppliers, manufacturers, and governments based on evolutionary game theory and analyzed the evolutionary stable strategies of their unilateral and joint behaviors. Further, system dynamics is applied to empirical analysis for exploring the dynamic interaction of the populations' strategy, and the key factors affecting ESS are also discussed in detail. Kang et al. [9] followed evolutionary low-carbon 
supply chain enterprise behavior and the strategic issues associated with government low-carbon policies and the emerging low-carbon market. The two levels supply chain consisting of a retailer and a manufacturer is established. A Stackelberg game approach is employed to solve four retailer and manufacturer low-carbon strategy combinations, after which these strategies are further analyzed using an evolutionary theoretical game approach, from which an evolutionary stability strategy is determined.

\subsection{The Impact of Government's Tax Policy on the Innovation} of High-Tech Enterprises. Most studies show that tax and fee policies will promote innovation by high-tech enterprises. Sun et al. [10] adopted the economic perspective of taxation policy to promote technological innovation and developed a taxation policy that could address the uncertain results of high-tech enterprises' innovation activities and the externalities of benefits to a certain extent. Qi et al. [11] believed that reduced preferential intensity can encourage enterprises to invest in R\&D. Kläser et al. [12] also verified that the R\&D super deduction policy has a significant tax incentive effect on enterprises. Chen and $\mathrm{Li}$ [13] explored the potential adverse effects of limiting tax incentives on corporate R\&D expenditures and found the negative impact of reducing $R \& D$ incentives to exceed the cost of reducing $R \& D$ investment.

In terms of government subsidies and tax credits, Chen et al. [14] found that government financial subsidies and tax incentives significantly improve the R\&D efficiency of hightech industries. Álvarez et al. [15] analyzed the effectiveness of public subsidies and tax credits used to promote longterm $\mathrm{R} \& \mathrm{D}$ investment and found that public subsidies are more effective for companies in which $R \& D$ investment is sustained and project quality is critical and that tax credits are suitable for promoting overall long-term R\&D investment. In addition to its positive promotional effect, many scholars also believe that tax and fee policies either have no significant impact on the innovation of high-tech enterprises or will have a negative impact. Song et al. [16] analyzed the impact of government financial incentive policies on the innovation performance of small and medium-sized hightech enterprises and found that government subsidies have a significant incentivizing effect on enterprise innovation while tax incentives not only cannot improve enterprise innovation performance but sometimes will also have a negative impact on such performance. Chen and Gupta [17] explored the relationship between taxation policies and $\mathrm{R} \& \mathrm{D}$ investment and found that when companies do not have beneficial innovation opportunities, tax incentives alone may not be able to effectively increase R\&D expenditures. Tian et al. [18] found that while tax relief for high-tech enterprises is positively correlated with R \& D efficiency, reduced $R \& D$ activities show a stable negative correlation with R\&D efficiency. Jia and Ma [19] evaluated the impact of tax incentives on corporate $R \& D$ expenditures and found that tax incentives significantly stimulate private enterprise R\&D but have almost no effect on state-owned enterprises' $\mathrm{R} \& \mathrm{D}$ expenditures.
In terms of research methods, most of the current research on the relationship between tax policy and corporate innovation uses qualitative analysis $[10,20]$ and quantitative empirical analysis methods. Among these methods, quantitative empirical analysis methods used mainly include the propensity score matching method [21, 22], the questionnaire survey method $[23,24]$, and panel data regression analysis $[11,17,25,26]$.

A review of the literature shows that existing research has laid a theoretical foundation for tax policy and corporate innovation research. Related research mainly focuses on the impact of tax preferential policies and government subsidies on corporate R\&D efficiency and R\&D investment and on the effectiveness of tax credit policies and their impacts on the technological innovation activities of enterprises, but results have not yet provided a unified conclusion. Existing research only concludes that the tax and fee policies have a positive or negative impact on the innovation capacities of high-tech enterprises and has not provided an in-depth discussion of its internal impact mechanism and marginal effects. Empirical research mainly uses historical data to verify existing assumptions. It is not possible to use such an approach to explore the impact of long-term development [27]. Moreover, while many scholars have recognized that evolutionary games are an important tool for analyzing the relationship between government and enterprises $[2,4,6,28,29]$, they have not yet used evolutionary game theory to analyze the impact of tax and fee policies on the innovation capabilities of high-tech enterprises.

In conclusion, the gaps in the literature fulfilled by this research are provided in the Authors' Contributions section (Table 1).

Therefore, to compensate for such gaps in the existing literature, this article makes the following contributions. (1) Evolutionary game theory is used to analyze the group behavior of participants from the perspective of bounded rationality to clearly describe the decision-making processes and learning behaviors of the government and high-tech enterprises and thus reveal the dynamic evolution processes of the two actors. (2) From the dynamic evolution process of the game between the government and enterprises, an evolutionary game model of the innovation behaviors of high-tech enterprises with the participation of the government is constructed, and internal mechanisms of the government designed to promote the innovation abilities of high-tech enterprises through tax policies and regulatory measures are examined. We analyze and strive to promote the improvement of high-tech enterprises' innovation capabilities and to provide valuable guidance for the adjustment of tax and fee policies among high-tech enterprises.

\section{Construction of the Evolutionary Game Model}

3.1. Theoretical Basis. At present, the Chinese government greatly incentivizes enterprises, especially those with hightech qualifications, to engage in innovation activities using corporate income tax and R\&D policies. Compared to traditional enterprises, high-tech enterprises pay more attention 
TABLE 1: Contribution of previous authors.

\begin{tabular}{lcccc}
\hline Author(s) & Government participation & Innovation behavior & Correlation & Research method \\
\hline Sun et al. [10] & Taxation policy & Developed & Significant & Qualitative analysis \\
Jia and Ma [19] & Tax incentive & R\&D expenditures & Insignificant & Qualitative analysis \\
Qi et al. [1] & Tax incentive & Innovation capability & Significant & Panel regression analysis \\
Chen and Li [13] & Tax incentive & R\&D incentives & Significant & Quantitative empirical analysis \\
Song et al. [16] & Tax incentive & Innovation performance & Insignificant & Quantitative empirical analysis \\
Chen et al. [14] & Taxation policy & R\&D efficiency & Significant & Quantitative empirical analysis \\
Kläser et al. [12] & Taxation policy & Developed & Significant & Quantitative empirical analysis \\
Chen and Gupta [17] & Taxation policy & R\&D incentives & Insignificant & Panel regression analysis \\
Liu et al. [27] & Government regulation & Developed & Significant & Evolutionary game \\
Zhu G. et al. [29] & Environmental supervision & Developed & Significant & Evolutionary game \\
Álvarez et al. [15] & Public subsidies & R\&D investment & Significant & Quantitative empirical analysis \\
This model & Government supervision & Developed & Significant & Evolutionary game \\
\hline
\end{tabular}

to technological innovation and engage continuously in hightech innovation through the intensive investment of $R \& D$ funds and talent. Although high-tech enterprises enjoy the competitive advantages brought about by continuous innovation, the application of new technologies and the opening of new markets are often highly risky and therefore require government support and guidance [22].

The universality, high transparency, and predictability of preferential tax policies can help companies make $\mathrm{R} \& \mathrm{D}$ decisions. Relevant research shows that after being recognized as high-tech enterprises, a series of preferential policies have a significant incentivizing effect on firms' innovation capabilities $[22,30]$. In terms of corporate income tax, hightech enterprise income tax is levied at a reduced tax rate of $15 \%$, which increases corporate cash flow and indirectly increases capital supply by reducing the taxable amount imposed on high-tech enterprises and reducing taxes [12]. In addition, this regulation has also addressed policy malpractice resulting from regional preferences, which has been conducive to ensuring fair competition among qualified high-tech enterprises. In terms of R\&D policies, the government has adopted super deduction as a preferential policy to encourage enterprises to increase R\&D investment and has further increased the pretax deduction ratio of research and development expenses for technology-based SMEs, which reflects the government's support for enterprise technology research and development. The greater the R\&D expenses of an enterprise are, the more expenses will be deducted accordingly, thereby reducing the enterprise's $\mathrm{R} \& \mathrm{D}$ risk, promoting the enterprise's technology $\mathrm{R} \& \mathrm{D}$ investment, and promoting the cultivation and development of high-tech talent. Whether an enterprise engages in $R \& D$ activity, whether it can obtain R\&D tax deductions, and the extent of the deductions depend entirely on its independent decision-making, which can further promote the autonomy of enterprise $R \& D$ and the improvement of enterprise $R \& D$ output and economic performance [31, 32]. In addition to providing policy incentives, to ensure that scientific and technological innovation activities are carried out in a standardized and orderly manner, the government will strengthen the supervision and management of recognized high-tech enterprises and penalize behaviors that violate the relevant regulations of high-tech enterprises in terms of innovation or operation activities.
The government applies incentives and sanctions on high-tech enterprises, and government actions have a direct impact on enterprise innovation. However, it may be that the stronger the incentives and sanctions become, the more they can promote the improvement of the innovative capabilities of high-tech enterprises. This problem can be analyzed using the marginal effect theory of economics. In economics, an increase in the consumption of goods or services by consumers will generally cause changes in the total income generated by such consumption. Under normal circumstances, for every additional unit of consumption of a product or service, the increase in revenue will gradually decrease; that is, the marginal effect will decrease accordingly. When the marginal effect gradual curve and marginal cost curve intersect at one point, the point of consumer spending relative to the product or service achieves the maximum benefit or degree of equilibrium [33, 34]. Therefore, this article discusses how the government can adjust tax and fee policies and sanctions to achieve the maximum benefits for high-tech enterprise innovation based on marginal effect theory.

3.2. Notations and Assumptions. Through an analysis of basic theory, this section builds an evolutionary game model based on whether the government participates in an incentive and supervision mechanism to promote the improvement of enterprise innovation capabilities. Based on this theory, the following basic notations are applied as shown in Table 2.

Based on the basic notations and their meanings in Table 2, some assumptions are proposed as follows:

(1) For a specific scientific and technological innovation activity, high-tech enterprises act as the main actors of innovation, and the government acts as the main body for incentives and supervision [4]. These two subjects constitute differentiated groups of limited rationality. High-tech enterprises seek to maximize their own benefits, and their behavioral goal is to engage in scientific and technological innovation activities or not [10]. The government pursues the maximum social benefits, and their behavioral options include adopting strong incentives and supervision or weak incentives and supervision [1]. 
TABLe 2: The basic notations.

\begin{tabular}{lc}
\hline Notation & Specific meaning and unit \\
\hline$R$ & The primary income of enterprises (million yuan) \\
$R^{\prime}$ & The increased income of enterprises (million yuan) \\
$I$ & The typical investment (million yuan) \\
$I^{\prime}$ & The total investment (million yuan) \\
$I_{1}$ & The expenditure on R\&D expenses (million yuan) \\
$I_{2}$ & The expenditure on form intangible assets (million yuan) \\
$T$ & The normal corporate income tax rate $(\%)$ \\
$T^{\prime}$ & The changed income tax rate $(\%)$ \\
$\alpha$ & The additional deduction coefficient $(\%)$ \\
$\beta$ & The amortization coefficient $(\%)$ \\
$n$ & The amortization period (year) \\
$S$ & The additional benefits (million yuan) \\
$C$ & The cost of the government's preparation and implementation (million yuan)
\end{tabular}

High-tech enterprises' engagement in scientific and technological innovation activities will be affected by government taxation and R\&D policies. Conversely, government taxation and $\mathrm{R} \& \mathrm{D}$ policies are also adjusted according to the actual needs of high-tech enterprises $[4,15]$. Both parties decide whether to engage in a certain scientific and technological innovation activity through a dynamic game process and finally reach a consistent equilibrium state through strategy selection.

(2) The typical income of high-tech enterprises is $R$, and the income generated from engaging in a specific scientific and technological innovation activity is $R^{\prime}$. After engaging in this activity, the total investment in technology development, personnel training, and the use of basic supporting facilities is $I^{\prime}$. Among these values, the expenditure on R\&D expenses is $I_{1}$, the expenditure on form intangible assets is $I_{2}$, $I^{\prime}=I_{1}+I_{2}$, and the typical investment that does not involve technological innovation activities is $I$.

(3) The income tax rate granted by the government to encourage high-tech enterprises to engage in certain innovative activities is $T^{\prime}$, and normal corporate income tax rate $T$ implements a deduction policy for companies actively engaged in research and development [11]. The additional deduction coefficient for internal independent research and development intangible asset expense expenditures is $\alpha$, the amortization coefficient of intangible assets from capitalization expenditures is $\beta$, and the amortization period is $n$. Under government incentives, enterprises also actively respond to the additional benefits brought to society by engaging in technological innovation activities $S$.

(4) The cost of the government's preparation and implementation (such as inspection and resource coordination) for a certain technological innovation activity adopted by high-tech enterprises is $C$ [17]. The government sanctions high-tech enterprises for violating relevant regulations of high-tech enterprises in their innovation or operation activities, and the punishment is denoted as F.

3.3. Evolutionary Game Revenue Matrix and Construction of Revenue Function. Assume that the probability of a hightech enterprise choosing to engage in scientific and technological innovation activities is $x$; then, the probability of not developing is $(1-x)$. The probability of the government applying strong incentives and supervision is $y$; then, the probability of applying weak incentives and supervision is $(1-y)$, and both $x$ and $y$ are functions of time $t$. According to our basic assumptions, under different strategies, the profit matrix of the two parties involved in the game is shown in Table 3.

Table 3 presents the income functions of high-tech enterprises and the government for different strategies. When the benefits of high-tech enterprises choosing to engage in or not engage in scientific and technological innovation activities are $U_{E 1}$ and $U_{S 1}$, respectively, and the expected return of the hybrid strategy is $\bar{U}_{1}$, the expressions of $U_{E 1}, U_{S 1}$, and $\bar{U}_{1}$ are as follows:

$$
\begin{aligned}
U_{E 1}= & y\left(R^{\prime}-I^{\prime}-\left[R^{\prime}-I_{1}(1+\alpha)-\frac{I_{2}(1+\beta)}{n}\right] T^{\prime}\right) \\
& +(1-y)\left(R^{\prime}-I^{\prime}-\left(R^{\prime}-I^{\prime}\right) T\right) \\
= & y\left\{\left(R^{\prime}-I^{\prime}\right) T+\left[R^{\prime}-I_{1}(1+\alpha)-\frac{I_{2}(1+\beta)}{n}\right] T^{\prime}\right\} \\
& +\left(R^{\prime}-I^{\prime}\right)(1-T), \\
U_{S 1}= & y(R-I-(R-I) T-F)+(1-y)(R-I-(R-I) T) \\
= & (R-I)(1-T)-y F, \\
\bar{U}_{1}= & x U_{E 1}+(1-x) U_{S 1} .
\end{aligned}
$$

When the government applies strong incentives and supervision and weak incentives and supervision to obtain 
TABLE 3: Government and enterprise income matrix.

\begin{tabular}{lccc}
\hline & \multicolumn{2}{c}{ Government } \\
& Strong incentives and supervision & Weak incentives and supervision \\
\hline \multirow{2}{*}{ Enterprise } & Develop & $R^{\prime}-I^{\prime}-\left[R^{\prime}-I_{1}(1+\alpha)-I_{2}(1+\beta) / n\right] T^{\prime} ;$ & $R^{\prime}-I^{\prime}-\left(R^{\prime}-I^{\prime}\right) T ;$ \\
& & {$\left[R^{\prime}-\alpha\left(1+I_{1}\right)-\beta\left(1+I_{2}\right) / n\right] T^{\prime}-C+S$} & $\left(R^{\prime}-I^{\prime}\right) T+S$ \\
& Not open & $R-I-(R-I) T-F ;$ & $R-I-(R-I) T ;$ \\
& $(R-I) T-C+F$ & $(R-I) T$ & $(R)$ \\
\hline
\end{tabular}

benefits $U_{E 2}$ and $U_{S 2}$, respectively, and the expected return of the hybrid strategy is $\bar{U}_{2}$, the expressions of $U_{E 2}, U_{S 2}$, and $\bar{U}_{2}$ are as follows:

$$
\begin{aligned}
U_{E 2} & =x\left\{\left[R^{\prime}-\alpha\left(1+I_{1}\right)-\frac{\beta\left(1+I_{2}\right)}{n}\right] T^{\prime}-C+S\right\}+(1-x)[(R-I) T-C+F] \\
& =x\left\{\left[R^{\prime}-\alpha\left(1+I_{1}\right)-\frac{\beta\left(1+I_{2}\right)}{n}\right] T^{\prime}+S-(R-I) T-F\right\}+(R-I) T-C+F, \\
U_{S 2} & =x\left[\left(R^{\prime}-I^{\prime}\right) T+S\right]+(1-x)(R-I) T \\
& =x\left[\left(R^{\prime}-I^{\prime}\right) T+S-(R-I) T\right]+(R-I) T, \\
\bar{U}_{2} & =y U_{E 2}+(1-y) U_{S 2} .
\end{aligned}
$$

\section{Solution of Evolutionary Stability Strategy Based on Dynamic Equation Copying}

To determine the dynamic process involved in copying the game between the government and high-tech enterprises, relevant evolutionary game theories and the calculation of expected returns are used to identify the dynamic evolutionary stable strategy between the government and hightech enterprises. Evolutionary game theory is premised on an evolutionarily stable strategy and replication dynamics [35]. For an evolutionarily stable strategy [36], the strategy is a stable equilibrium strategy, if and only if the following happens:

(1) $s^{*}$ constitutes a Nash equilibrium; for any strategy $s$, we have $u\left(s^{*}, s^{*}\right) \geq u\left(s^{*}, s\right)$;

(2) Assuming that $s^{*} \neq s$ satisfies $u\left(s^{*}, s^{*}\right)=u\left(s^{*}, s\right)$, we have $u\left(s^{*}, s^{*}\right)>u\left(s^{*}, s\right)$.
The replication dynamic is mainly used to describe the dynamic differential equation of the frequency or probability of a strategy being used in a certain population expressed as follows [37, 38]:

$$
f(k)=\frac{\mathrm{d} x_{k}}{\mathrm{~d} t}=x_{k}[u(k, s)-u(s, s)], \quad k=1,2,3, \ldots, K,
$$

where $x_{k}$ is the probability of a certain population using strategy $k, u(k, s)$ is the fitness of using strategy $k$, and $u(s, s)$ is its average fitness. In addition, for strategy $k$ to become an evolutionarily stable strategy, it must satisfy $f(k)=0$ and $f^{\prime}(k)<0$.

According to the above theories and formulas, the dynamic equations of replication and their evolutionary stability strategies for high-tech enterprises and governments are solved. The evolutionary replication dynamic equation for high-tech enterprises engaged in scientific and technological innovation activities is as shown as follows:

$$
\begin{aligned}
f(x) & =\frac{\mathrm{d} x}{\mathrm{~d} t}=x\left(U_{E 1}-\bar{U}_{1}\right)=x\left(U_{E 1}-x U_{E 1}-(1-x) U_{S 1}\right)=x(1-x)\left(U_{E 1}-U_{S 1}\right) \\
& =x(1-x)\left\{y\left\{\left(R^{\prime}-I^{\prime}\right) T+\left[R^{\prime}-I_{1}(1+\alpha)-\frac{I_{2}(1+\beta)}{n}\right] T^{\prime}\right\}+\left(R^{\prime}-I^{\prime}\right)(1-T)-(R-I)(1-T)+y F\right\} \\
& =x(1-x)\left\{y\left\{\left(R^{\prime}-I^{\prime}\right) T+\left[R^{\prime}-I_{1}(1+\alpha)-\frac{I_{2}(1+\beta)}{n}\right] T^{\prime}+F\right\}+\left(R^{\prime}-I^{\prime}\right)(1-T)-(R-I)(1-T)\right\} \\
& =x(1-x)\left\{y\left\{\left(R^{\prime}-I^{\prime}\right) T+\left[R^{\prime}-I_{1}(1+\alpha)-\frac{I_{2}(1+\beta)}{n}\right] T^{\prime}+F\right\}+\left(R^{\prime}-I^{\prime}-R+I\right)(1-T)\right\} .
\end{aligned}
$$


The second derivative of equation (4) is as follows:

$$
\begin{aligned}
f^{\prime}(x) & =\frac{\mathrm{d}^{2} x}{\mathrm{~d} t^{2}} \\
& =(1-2 x)\left\{y\left\{\left(R^{\prime}-I^{\prime}\right) T+\left[R^{\prime}-I_{1}(1+\alpha)-\frac{I_{2}(1+\beta)}{n}\right] T^{\prime}+F\right\}+\left(R^{\prime}-I^{\prime}-R+I\right)(1-T)\right\} .
\end{aligned}
$$

Let $(\mathrm{d} x / \mathrm{d} t)=0$ and we can then write the solution to the copied dynamic equation as $x^{*}=0, x^{*}=1$, and $y^{*}=\left(\left(I^{\prime}+\right.\right.$ $\left.R-R^{\prime}-I\right)(1-T) /\left(R^{\prime}-I^{\prime}\right) T+\left[R^{\prime}-I_{1}(1+\alpha)-I_{2}(1+\beta\right.$ )$\left./ n] T^{\prime}+F\right)$. Therefore, according to the judgment conditions of the evolutionary stability strategy, the following three evolutionary stability strategies available for high-tech enterprises to engage in technological innovation activities are obtained.

(1) When $y=y^{*}=\left(\left(I^{\prime}+R-R^{\prime}-I\right)(1-T) /\left(R^{\prime}-I^{\prime}\right)\right.$ $\left.T+\left[R^{\prime}-I_{1}(1+\alpha)-I_{2}(1+\beta) / n\right] T^{\prime}+F\right), \quad f(x)=$ 0 , and $f^{\prime}(x)=0$ are obtained for any $x$, then all $x$ values are in a stable state. Therefore, when the probability of the government implementing strong incentives and supervision to promote high-tech enterprises to engage in technological innovation activities is $\left(\left(I^{\prime}+R-R^{\prime}-I\right)(1-T) /\left(R^{\prime}-I^{\prime}\right) T+\right.$ $\left.\left[R^{\prime}-I_{1}(1+\alpha)-I_{2}(1+\beta) / n\right] T^{\prime}+F\right)$, the probability of high-tech enterprises engaging in technological innovation activities is stable as shown in Figure 1(a).

(2) When $y>y^{*}=\left(\left(I^{\prime}+R-R^{\prime}-I\right)(1-T) /\left(R^{\prime}-I^{\prime}\right)\right.$ $\left.T+\left[R^{\prime}-I_{1}(1+\alpha)-I_{2}(1+\beta) / n\right] T^{\prime}+F\right), f(1)=0$, and $f^{\prime}(1)<0$ are obtained according to the dynamic replication equation, $x^{*}=1$ is an evolutionarily stable strategy. That is, when the probability of the government implementing incentives and regulatory measures reaches $\left(\left(I^{\prime}+R-\right.\right.$ $\left.R^{\prime}-I\right)(1-T) /\left(R^{\prime}-I^{\prime}\right) T+\left[R^{\prime}-I_{1}(1+\alpha)-I_{2}(1\right.$ $\left.+\beta) / n] T^{\prime}+F\right)$ and continues to increase, the probability of high-tech enterprises engaging in scientific and technological innovation activities gradually increases and will eventually develop as their best strategic plan as shown in Figure 1(b).

(3) When $y<y^{*}=\left(\left(I^{\prime}+R-R^{\prime}-I\right)(1-T) /\left(R^{\prime}-I^{\prime}\right)\right.$ $\left.T+\left[R^{\prime}-I_{1}(1+\alpha)-I_{2}(1+\beta) / n\right] T^{\prime}+F\right), f(0)=0$, and $f^{\prime}(0)<0$ are obtained according to the replication dynamic equation, $x^{*}=0$ is an evolutionarily stable strategy; that is, when the probability of the government implementing incentives and regulatory measures is less than $\left(\left(I^{\prime}+R-R^{\prime}-I\right)(1-T) /\left(R^{\prime}-I^{\prime}\right) T+\left[R^{\prime}-I_{1}(1+\right.\right.$ $\left.\left.\alpha)-I_{2}(1+\beta) / n\right] T^{\prime}+F\right)$ and continues to decrease, the probability of high-tech enterprises engaging in technological innovation activities gradually decreases and eventually will not emerge as the best strategy as shown in Figure 1(c).

With the same specifications, the dynamic equation for the evolution and replication of the government's implementation of incentive and regulatory measures is shown in equation (6):

$$
\begin{aligned}
f(y)= & \frac{\mathrm{d} y}{\mathrm{~d} t}=y\left(U_{E 2}-\bar{U}_{2}\right) \\
= & y\left[U_{E 2}-y U_{E 2}-(1-y) U_{S 2}\right]=y(1-y)\left(U_{E 2}-U_{S 2}\right) \\
& \left.\left.=y(1-y)\left\langle\quad x\left\{\left[R^{\prime}-\alpha\left(1+I_{1}\right)-\frac{\beta\left(1+I_{2}\right)}{n}\right] T^{\prime}+S-(R-I) T-F\right\}\right\rangle\right)\right\rangle \\
& +(R-I) T-C+F-x\left[\left(R^{\prime}-I^{\prime}\right) T+S-(R-I) T\right]-(R-I) T \\
= & y(1-y)\left\langle\begin{array}{c}
\left.x\left\{\left[R^{\prime}-\alpha\left(1+I_{1}\right)-\frac{\beta\left(1+I_{2}\right)}{n}\right] T^{\prime}+S-(R-I) T-F\right\}\right) \\
n
\end{array}\right] \\
= & y(1-y)\left\langle x\left\{\left[R^{\prime}-\alpha\left(1+I_{1}\right)-\frac{\beta\left(1+I_{2}\right)}{n}\right] T^{\prime}-F-\left(R^{\prime}-I^{\prime}\right) T\right\}-C+F\right\rangle .
\end{aligned}
$$




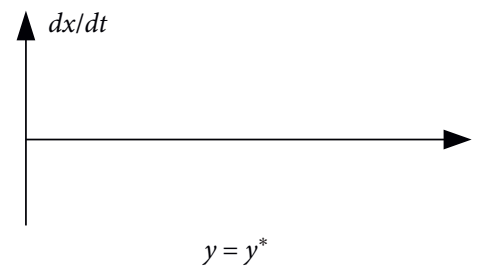

(a)

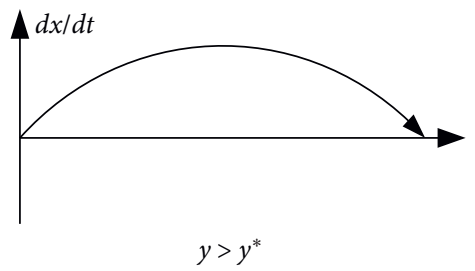

(b)

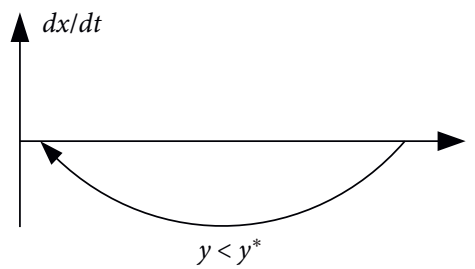

(c)

Figure 1: Reproduction dynamic phase diagram for high-tech enterprises.

The second derivative of equation (6) is as follows:

$$
f^{\prime}(y)=\frac{\mathrm{d}^{2} y}{\mathrm{~d} t^{2}}=(1-2 y)\left\langle x\left\{\left[R^{\prime}-\alpha\left(1+I_{1}\right)-\frac{\beta\left(1+I_{2}\right)}{n}\right] T^{\prime}-F-\left(R^{\prime}-I^{\prime}\right) T\right\}-C+F\right\rangle .
$$

Let $(\mathrm{d} y / \mathrm{d} t)=0$, and the solution of the copy dynamic equation is $y^{*}=0, y^{*}=1$, and $x^{*}=\left(C-F /\left[R^{\prime}-\alpha(1+\right.\right.$ $\left.\left.\left.I_{1}\right)-\beta\left(1+I_{2}\right) / n\right] T^{\prime}-F-\left(R^{\prime}-I^{\prime}\right) T\right)$.

According to the judgment conditions of the evolutionary stability strategy, the following three evolutionary stability strategies available for the government to implement incentive and regulatory measures are obtained.

(1) When $x=x^{*}=\left(C-F /\left[R^{\prime}-\alpha\left(1+I_{1}\right)-\beta\left(1+I_{2}\right)\right.\right.$ $\left.\ln ] T^{\prime}-F-\left(R^{\prime}-I^{\prime}\right) T\right), \quad f(y)=0$, and $f^{\prime}(y)=0$ are obtained for any $y$, ally values are in a stable state. Therefore, when the probability of high-tech enterprises engaging in scientific and technological innovation activities is $m$, the likelihood of the government implementing strong incentives and supervision is stable, as shown in Figure 2(a).

(2) When $x>x^{*}=\left(C-F /\left[R^{\prime}-\alpha\left(1+I_{1}\right)-\beta\left(1+I_{2}\right)\right.\right.$ $\left./ n] T^{\prime}-F-\left(R^{\prime}-I^{\prime}\right) T\right), f(1)=0$, and $f^{\prime}(1)<0$ are obtained according to the replication dynamic equation, $y^{*}=1$ is an evolutionarily stable strategy; that is, when the probability of high-tech enterprises engaging in scientific and technological innovation activities reaches $\left(C-F /\left[R^{\prime}-\alpha\left(1+I_{1}\right)\right.\right.$ $\left.\left.-\beta\left(1+I_{2}\right) / n\right] T^{\prime}-F-\left(R^{\prime}-I^{\prime}\right) T\right)$ and continues to increase, the intensity of government incentives and supervision also increases, and strong incentives and supervision are taken as the best strategy as shown in Figure 2(b).

(3) When $x<x^{*}=\left(C-F /\left[R^{\prime}-\alpha\left(1+I_{1}\right)-\beta\left(1+I_{2}\right)\right.\right.$ $\left.[n] T^{\prime}-F-\left(R^{\prime}-I^{\prime}\right) T\right), f(0)=0$, and $f^{\prime}(0)<0$ are obtained according to the replication dynamic equation, $y^{*}=0$ is an evolutionarily stable strategy. Therefore, when the probability of high-tech enterprises engaging in scientific and technological innovation activities is less than $\left(C-F /\left[R^{\prime}-\alpha(1+\right.\right.$ $\left.\left.\left.I_{1}\right)-\beta\left(1+I_{2}\right) / n\right] T^{\prime}-F-\left(R^{\prime}-I^{\prime}\right) T\right)$ and gradually declines, the intensity of government incentives and supervision will also decline, and weak incentives and supervision will eventually constitute the best strategy as shown in Figure 2(c).

According to the above analysis, the dynamic game evolution path of advanced enterprises and governments is comprehensively shown in Figure 3. In Figure 3, points $\mathrm{O}$ and $\mathrm{B}$ denote the evolutionary and stable strategies available for high-tech enterprises and the government to jointly engage in scientific and technological innovation activities, and the stable strategy to which the system finally converges 


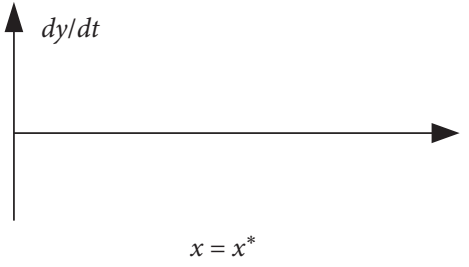

(a)

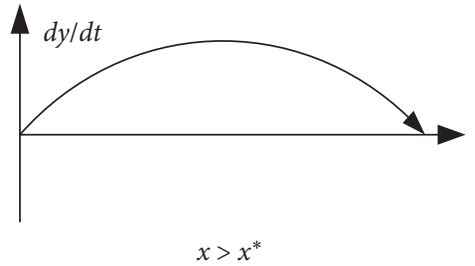

(b)

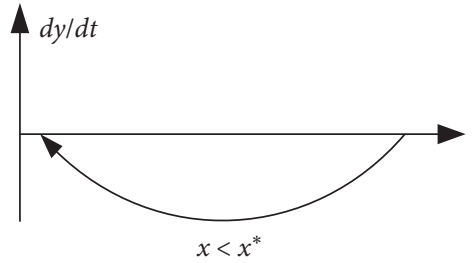

(c)

FIGURE 2: Government's replication dynamic phase diagram.

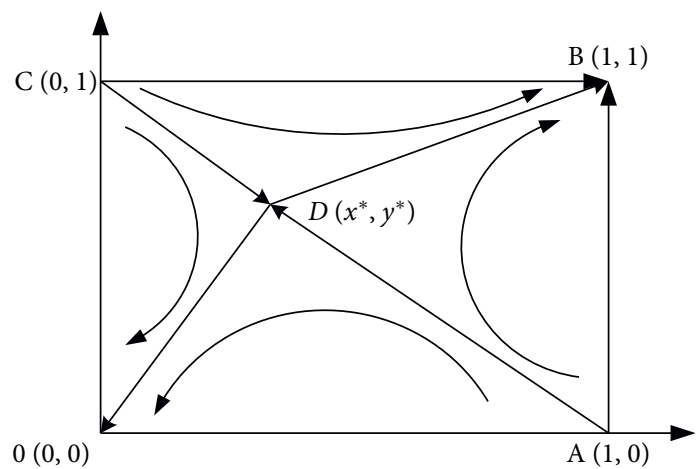

FIGURE 3: Evolution path of the dynamic game between high-tech enterprises and the government.

depends on the selection of both sides of the game. When the selection of high-tech enterprises and the government are located in the AOC area, the system evolution strategy will eventually converge to point $\mathrm{O}(0,0)$; that is, high-tech enterprises will not engage in scientific and technological innovation activities, and the government will choose to implement weak incentives and regulatory measures. The government then does not implement effective incentives and regulatory measures, and high-tech enterprises have no motivation to engage in new technological innovation activities. When the initial strategy of high-tech enterprises and the government is located in the ABC area, the system evolution strategy will eventually converge to point $\mathrm{B}(1,1)$; that is, high-tech enterprises will engage in scientific and technological innovation activities, and the government will choose to implement strong incentives and regulatory measures. The government then implements effective incentive and regulatory measures, and high-tech enterprises actively engage in scientific and technological innovation activities to enhance their innovation capabilities. Point B $(1,1)$ denotes an ideal stable strategy, and the parameters should be adjusted to render the system most likely to converge to Pareto optimal equilibrium point $\mathrm{B}(1,1)$. Then, the chosen strategy of both parties should be located in the $\mathrm{ABC}$ area $x>x^{*}, y>y^{*}$.

According to the influencing factors of the equilibrium point, the lower the income tax rate $T^{\prime}$ for high-tech enterprises, the general corporate income tax rate $T$, the intangible asset expense expenditure plus the deduction coefficient $\alpha$, the capitalization expense forming the intangible asset amortization coefficient $\beta$, and the administrative penalty amount are, the larger $F$ is, and the more likely the 
equilibrium point will tend to be point $B$. Theoretically, the government can increase the tax incentives and additional deductions and administrative penalties of high-tech enterprises such that $x>x^{*}, y>y^{*}$, causing high-tech enterprises to actively engage in scientific and technological innovation activities as their optimal strategy and improving their corporate innovation capabilities. This approach optimizes the industrial structure, but to determine if it can truly promote the innovation abilities of high-tech enterprises, it is necessary to simulate the influence of the abovementioned related parameters on the evolution of the system.

\section{Numerical Simulation and Result Analysis}

Based on the above demonstration of the influence of changes in various factors on the strategic choices of game players, the evolutionary law of high-tech enterprise innovation behavior under government participation is further analyzed. In this study, MATLAB software is used for simulation to explore the evolution of the system with numerical changes in the main parameters. To investigate the innovation activities and operating conditions of hightech enterprises, a 30-person team of experts was established to analyze key indicator data and score points to obtain corresponding indicator weights as reliable data for numerical simulation analysis.

The incomes of high-tech enterprises before and after scientific and technological innovation activities are $R=200$ and $R^{\prime}=235$, respectively, and corresponding $R \& D$ investment values $I=30$ and $I^{\prime}=75$, respectively. For the investment in scientific and technological innovation activities, the research and development expenditure is $I_{1}=25$, the expenditure for forming intangible assets is $I_{2}=50$, and additional social benefits are denoted by $S=30$. At present, the general corporate income tax rate and hightech corporate income tax rate set by the Chinese government are $T=0.25$ and $T^{\prime}=0.15$, respectively. The additional deduction coefficient for intangible asset expenditure is $\alpha=75 \%$, the cost amortization coefficient for intangible assets formed by capital expenditure is $\beta=75 \%$, the amortization period is $n=10$, the administrative penalty is $F=10$, and the government supervision cost allocated to each enterprise is $C=5$. Based on the above data, the impact of the main parameter changes on system evolution is analyzed.

We analyze the impact of the high-tech enterprise income tax rate on system evolution as shown in Figure 4. For the scenario where the initial probability is 0.5 , the values are $0.25,0.20,0.15,0.10$, and 0.05 . In the early stages of the tax policy announcement, as the government increased its preferential income tax rate for high-tech enterprises, the rate at which high-tech enterprises participated in innovation activities to the Pareto optimal "ideal point" gradually accelerated, and the smaller the $T^{\prime}$ value was, the faster evolution became. When $T^{\prime}$ takes a value of 0.20 , the system starts to converge to the "nonideal point." As the value of $T^{\prime}$ increases, the system converges to the "nonideal point" faster.
In addition, although the smaller the value of $t$ is, the more common the evolution of the system to the "ideal point" becomes, when $T^{\prime}$ reaches the critical value of 0.1 , the rate of system evolution begins to stabilize. Thus, when the income tax rate of high-tech enterprises is lower than 0.1 , it will no longer effectively motivate high-tech enterprises to increase investment in innovation activities.

We next analyze the impact of the general corporate income tax rate $T$ on enterprises' motivation to participate in innovation activities and transform into high-tech enterprises as shown in Figure 5. When the initial probability value is $0.5, t$ takes values of $0.35,0.30,0.25,0.20$, and 0.15 .

In the initial stage of the general corporate income tax rate $(t=0.08$ is the critical value in Figure 5$)$, the change in the $T$ value shows no obvious difference in the impact of enterprises' participation in innovation activities and transformation into high-tech enterprises through "convergence."

Over time, after crossing the time threshold of $t=0.08$, as the government sets the higher general corporate income tax rate $T$, enterprises' motivation to participate in innovation activities and transform into high-tech enterprises evolves to an "ideal point" faster. Conversely, the lower the general corporate income tax rate is, the faster a company participates in innovative activities and transforms into a high-tech enterprise, which will gradually accelerate its evolution toward "nonideal points." That is, the higher the general corporate income tax rate is, the greater the probability of companies choosing to engage in technological innovation activities will become and the more motivated such firms will be to transform into high-tech enterprises.

We next analyze the impact of the additional deduction coefficient and amortization coefficient $\alpha, \beta$ on the participation of high-tech enterprises in innovation activities and the improvement of innovation capabilities, as shown in Figure 6. According to China's R\&D super deduction policy, the super deduction coefficient and amortization coefficient are the same. For this reason, in our simulation, the two coefficients are set the same, and $\alpha, \beta$ are set as $0.1,0.3,0.5$, 0.7 , and 0.9 . Under an initial probability of 0.5 , over time, for enterprises subject to the R\&D super deduction policy, the higher the super deduction and amortization coefficients become, the more motivated enterprises are to participate in innovation and R\&D activities, and the faster the simulation system evolves to the "ideal point." The lower the additional deduction coefficient and amortization coefficient are, the slower the system evolves to the "ideal point." In addition, from the simulation results, the size of the R\&D super deduction coefficient and amortization coefficient cannot hinder the enterprise's R\&D and participation activities. Because the enterprise itself has a profitable mission, to increase its profitability, the enterprise itself can cater its products to the needs of $\mathrm{R} \& \mathrm{D}$ activities, and the government's R \& D super deduction for enterprise R\&D further rewards enterprise innovation activities.

Our analysis of the impact of government administrative penalties on high-tech enterprises' participation in innovation activities and improvements of innovation capabilities is shown in Figure 7. Since there is no quantified 


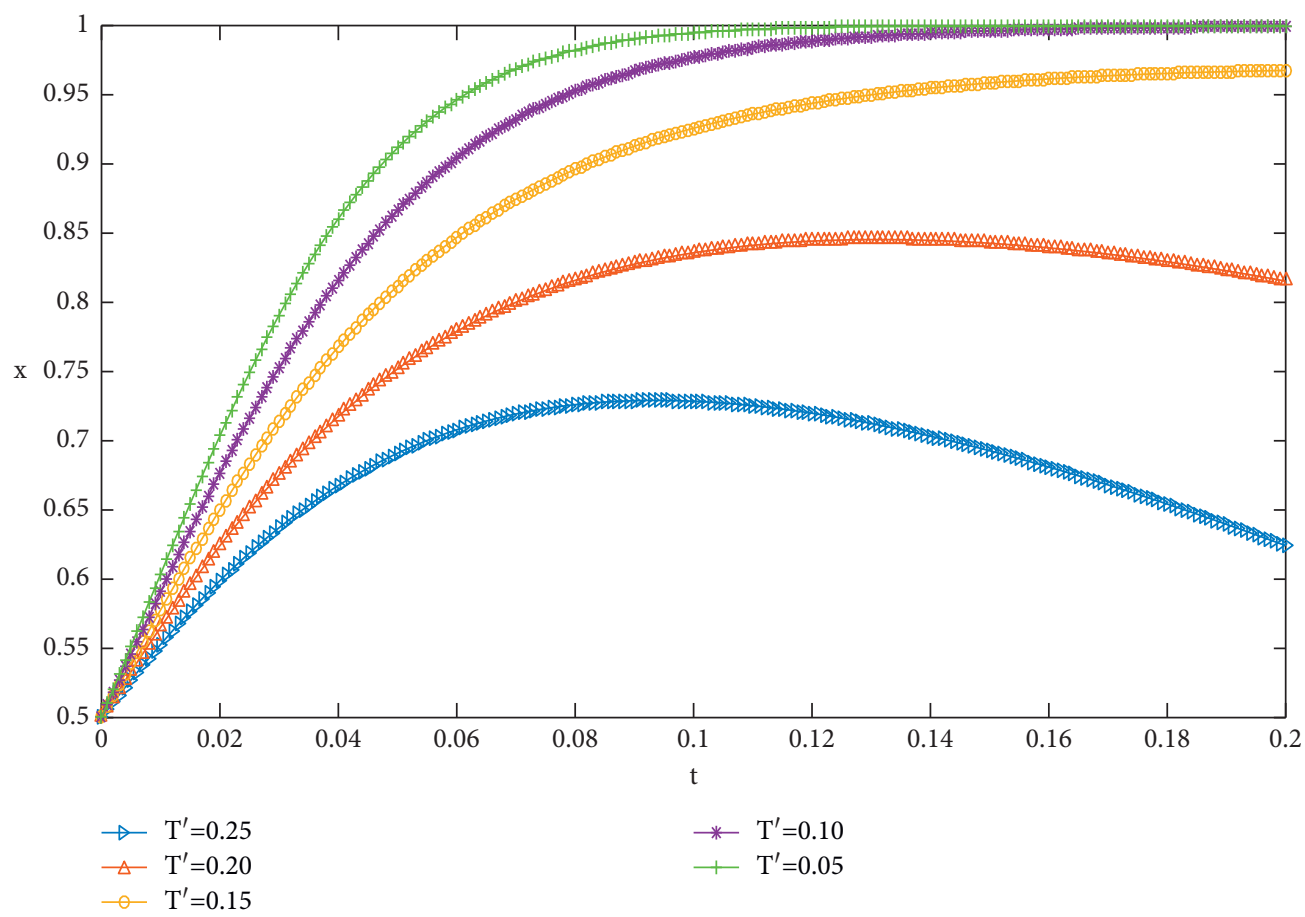

FIgURE 4: Impact of the high-tech enterprise income tax rate on system evolution.

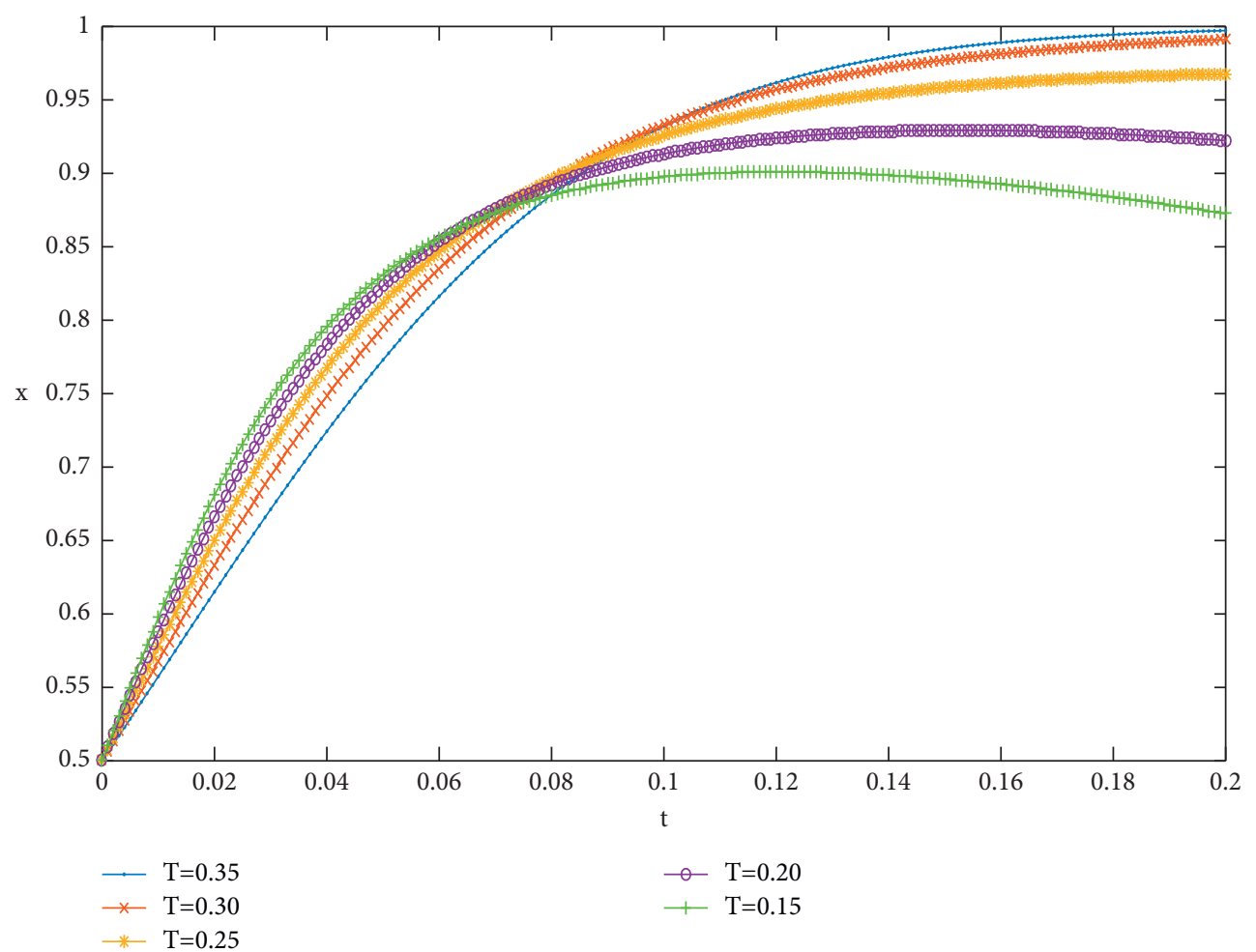

Figure 5: Impact of general corporate income tax rates on system evolution.

administrative penalty standard, values of $0,5,10,15$, and 25 are applied in the simulation. For the scenario with an initial probability of 0.5 , over time, the greater the government's administrative penalties on high-tech enterprises become, the more vigilant the enterprises will be to improve their own operating conditions, enhance their innovation capabilities, and avoid being eliminated. The rate of evolution to the ideal point gradually increases. Conversely, the lower the administrative penalty is, the faster the system will evolve to "nonideal points." In addition, when the intensity of 


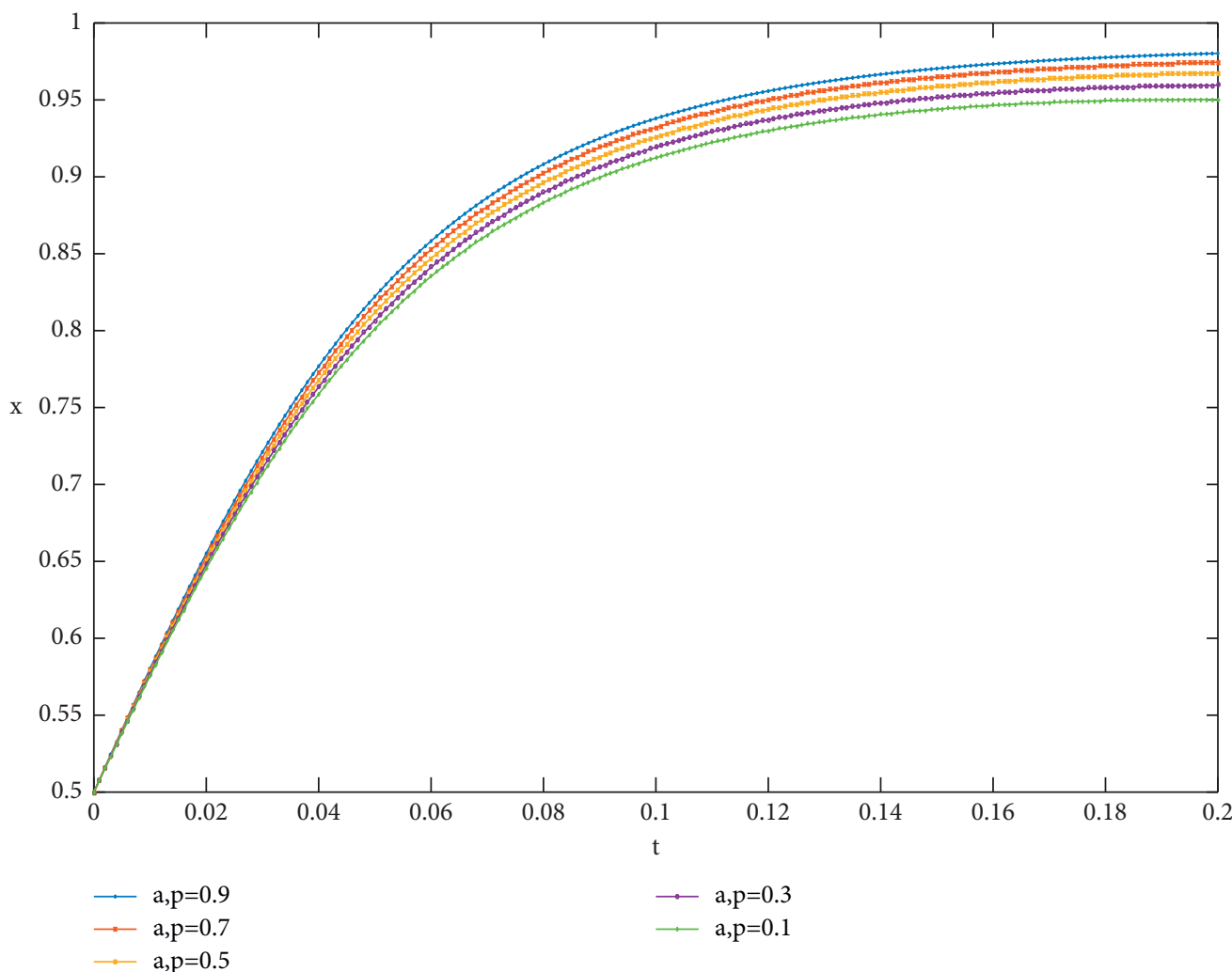

Figure 6: Influence of the additional deduction coefficient and amortization coefficient on system evolution.

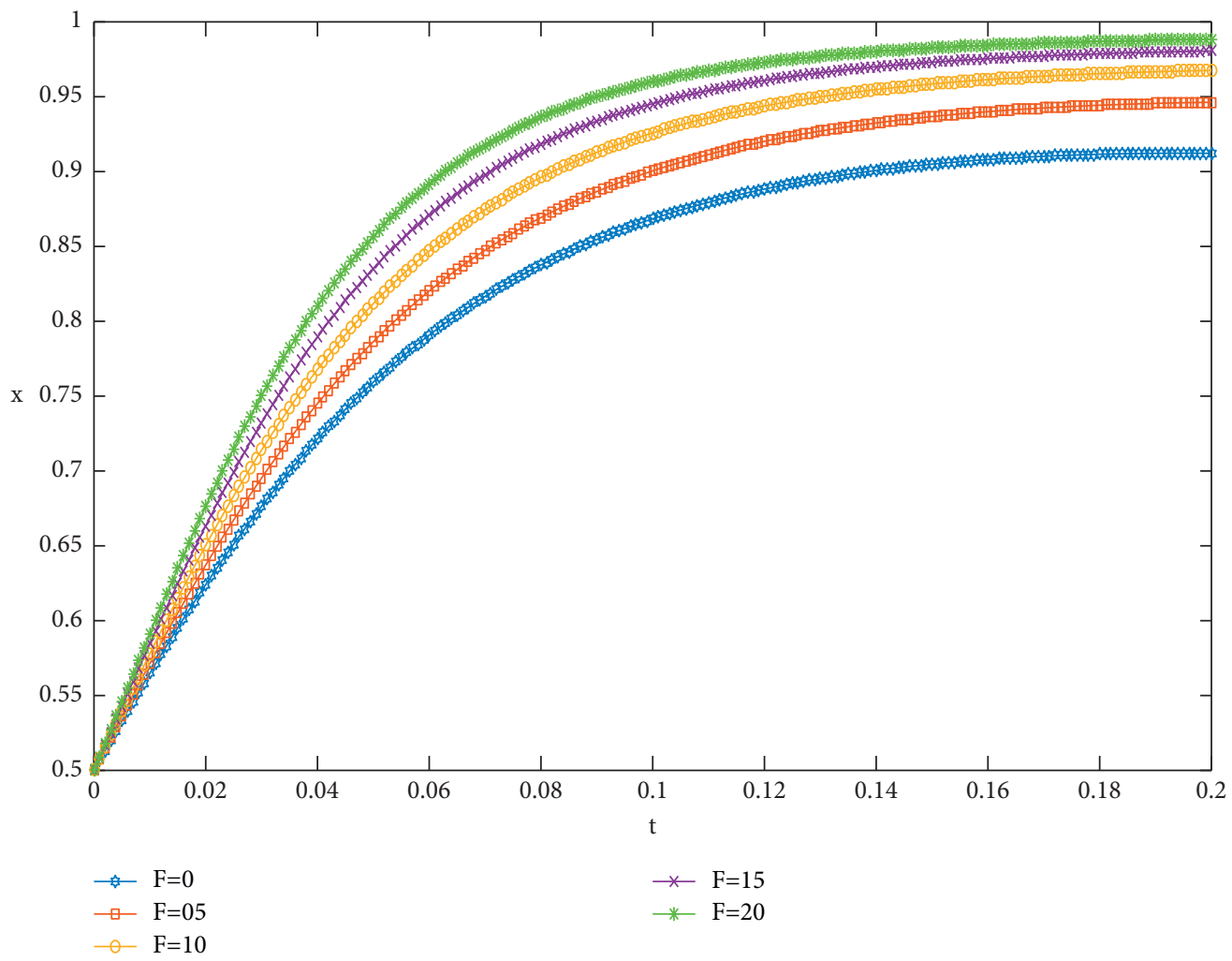

FIGURE 7: Impact of administrative penalties on system evolution. 
administrative penalties reaches a certain level, that is, when the value exceeds 15, the marginal effects of administrative penalties on the improvement of high-tech enterprises' operating conditions and the enhancement of innovation capabilities begin to decline, and eventually their effects become consistent.

\section{Conclusion}

This paper uses evolutionary game theory and MATLAB numerical simulations to analyze the internal mechanisms and marginal effects of high-tech enterprises' innovation capabilities under government tax and fee policy incentives and regulatory measures. The results show that, in terms of the internal mechanisms of government tax and fee policy incentives and regulatory measures to promote high-tech enterprise innovation, including lower hightech enterprise income tax rates, higher general corporate income tax rates, additional deduction and amortization coefficients, and an increase in regulatory agencies, all administrative penalties can encourage enterprises to engage in scientific and technological innovation. In terms of the marginal effects of incentives, when the high-tech enterprise income tax rate drops below 0.1, the marginal effect of incentives is reduced; when the administrative penalty is too high, the marginal effect of incentives is reduced, the general corporate income tax rate increases, and the deduction and amortization coefficients have little effect on the marginal effects of incentives. As means to maximize incentives for high-tech enterprises to engage in scientific and technological innovation activities and enhance their innovation capabilities, the following countermeasures are proposed.

Regarding the corporate income tax rate, the government can mobilize enterprises to engage in scientific and technological innovation activities through a "one drop and one rise" policy, thereby enhancing the innovation capabilities of enterprises. Under a "one reduction" approach, the government further encourages enterprises to participate in scientific and technological innovation activities by reducing the income tax rate of high-tech enterprises, but attention should be given to controlling tax reductions to within a certain range. If the income tax rate of high-tech enterprises is reduced too much, the marginal effect of incentives will be reduced, which will not maximize the improvement of corporate innovation capabilities and social benefits. Under a "one-liter" approach, the government can increase the general corporate income tax rate to promote the active participation of general enterprises in innovation and R\&D activities, enhancing their innovation capabilities and actively promoting high-tech business transformation.

Regarding the super deduction policy, the super deduction and amortization coefficients still show much room for improvement. The government can further appropriately increase the super deduction and amortization coefficients to motivate enterprises to engage in scientific and technological innovation and conduct research, and the investment of funds and $R \& D$ personnel will further enhance the innovation capabilities of high-tech enterprises.
In terms of regulatory measures, the government can improve the innovation activities of enterprises by increasing administrative supervision penalties. The greater the administrative penalties imposed by the government on high-tech enterprises are, the more vigilant enterprises will be to improve their operating conditions, enhance their innovation capabilities, and avoid being eliminated. However, the extent of penalties must be controlled within a reasonable range to prevent administrative penalties from reducing the marginal effects of improving the operating conditions and enhancing the innovation capabilities of high-tech enterprises.

In future work, we can further add consumers [39-42] into the game pattern between enterprises and the government, thus exploring the game behavior among government, enterprises, and consumers on innovation activities based on the tripartite game model. In addition, social welfare [43], environmental protection [44], and other factors can be considered to be added to the model, so as to examine more extensive influencing factors of the game behavior between the government and enterprises.

\section{Data Availability}

No data were used to support this study.

\section{Conflicts of Interest}

The authors declare that they have no conflicts of interest.

\section{Authors' Contributions}

Chen Gong conceptualized the study, was responsible for funding acquisition, software, provided the resources, performed data curation, performed supervision, and reviewed and edited the article. Jian Liu conceptualized the study, performed data curation, performed supervision, performed investigation, reviewed and edited the article. Jinping Chang performed formal analysis, performed investigation, performed supervision, provided the resources, and performed data curation.

\section{Acknowledgments}

This study was funded through the "Heilongjiang Province General Undergraduate Colleges and Universities Youth Innovative Talent Training Program" (UNPYSCT-2020075).

\section{References}

[1] P. Assarzadegan, S. R. Hejazi, and G. A. Raissi, "An evolutionary game theoretic model for analyzing retailers' behavior when introducing economy and premium private labels," Journal of Retailing and Consumer Services, vol. 57, Article ID 102227, 2020.

[2] Y. Shi, B. Han, and Y. Zeng, "Simulating policy interventions in the interfirm diffusion of low-carbon technologies: an agent-based evolutionary game model," Journal of Cleaner Production, vol. 250, Article ID 119449, 2020.

[3] Z. Tian, X. Gao, S. Su, J. Qiu, X. Du, and M. Guizani, "Evaluating reputation management schemes of internet of 
vehicles based on evolutionary game theory," IEEE Transactions on Vehicular Technology, vol. 68, no. 6, pp. 5971-5980, 2019.

[4] W. Chen and Z. H. Hu, "Using evolutionary game theory to study governments and manufacturers' behavioral strategies under various carbon taxes and subsidies," Journal of Cleaner Production, vol. 201, pp. 123-141, 2018.

[5] B. Kang, G. Chhipi-Shrestha, Y. Deng, K. Hewage, and R. Sadiq, "Stable strategies analysis based on the utility of Z-number in the evolutionary games," Applied Mathematics and Computation, vol. 324, pp. 202-217, 2018.

[6] M. Zhang, Q. Zhang, D. Zhou, and L. Wang, "Punishment or reward? strategies of stakeholders in the quality of photovoltaic plants based on evolutionary game analysis in China," Energy, vol. 220, Article ID 119754, 2021.

[7] Z. Yu and S. A. Rehman Khan, "Evolutionary game analysis of green agricultural product supply chain financing system: COVID-19 pandemic," International Journal of Logistics Research and Applications, vol. 4, pp. 1-21, 2021.

[8] J. Xu, J. Cao, Y. Wang, X. Shi, and J. Zeng, "Evolutionary game on government regulation and green supply chain decisionmaking," Energies, vol. 13, no. 3, p. 620, 2020.

[9] K. Kang, Y. Zhao, J. Zhang, and C. Qiang, "Evolutionary game theoretic analysis on low-carbon strategy for supply chain enterprises," Journal of Cleaner Production, vol. 230, pp. 981-994, 2019.

[10] Z. Sun, X. Wang, C. Liang, F. Cao, and L. Wang, "The impact of heterogeneous environmental regulation on innovation of high-tech enterprises in China: mediating and interaction effect," Environmental Science and Pollution Research, vol. 28, no. 7, pp. 8323-8336, 2021.

[11] Y. Qi, W. Peng, and N. N. Xiong, "The effects of fiscal and tax incentives on regional innovation capability: text extraction based on python," Mathematics, vol. 8, no. 7, p. 1193, 2020.

[12] J. Kläser, M. Lachenal, and T. Nabholz, "Promoting innovation through tax policy in Switzerland," International Tax Review, 2021, In press.

[13] M. C. Chen and H. Y. Li, "The effects and economic consequences of cutting R \& D tax incentives," China Journal of Accounting Research, vol. 11, no. 4, pp. 367-384, 2018.

[14] H. Chen, H. Lin, and W. Zou, "Research on the regional differences and influencing factors of the innovation efficiency of China's high-tech industries: based on a shared inputs twostage network DEA," Sustainability, vol. 12, no. 8, p. 3284, 2020.

[15] I. C. Álvarez-Ayuso, C. Kao, and D. Romero-Jordán, "Long run effect of public grants and tax credits on R\&D investment: a non-stationary panel data approach," Economic Modelling, vol. 75, pp. 93-104, 2018.

[16] M. Song, S. Wang, and H. Zhang, "Could environmental regulation and $\mathrm{R} \& \mathrm{D}$ tax incentives affect green product innovation?" Journal of Cleaner Production, vol. 258, Article ID 120849, 2020.

[17] M. C. Chen and S. Gupta, "The incentive effects of R\&D tax credits: an empirical examination in an emerging economy," Journal of Contemporary Accounting \& Economics, vol. 13, no. 1, pp. 52-68, 2017.

[18] B. Tian, B. Yu, S. Chen, and J. Ye, "Tax incentive, R\&D investment and firm innovation: evidence from China," Journal of Asian Economics, vol. 71, Article ID 101245, 2020.

[19] J. Jia and G. Ma, "Do R \& D tax incentives work? firm-level evidence from China," China Economic Review, vol. 46, pp. 50-66, 2017.
[20] Y. Shao and C. Xiao, "Corporate tax policy and heterogeneous firm innovation: evidence from a developing country," Journal of Comparative Economics, vol. 47, no. 2, pp. 470-486, 2019.

[21] O. Ivus, M. Jose, and R. Sharma, "R \& D tax credit and innovation: evidence from private firms in India," Research Policy, vol. 50, no. 1, pp. 104-128, 2021.

[22] P. Deng and H. Lu, "Transnational knowledge transfer or indigenous knowledge transfer: which channel has more benefits for China's high-tech enterprises?” European Journal of Innovation Management, 2021, In press.

[23] Q. Wang, G. Li, and H. Yang, "Chip war" enlightenment: the effect of value-added tax on investment and research and development of high-tech enterprises," Journal of Management Policy and Practice, vol. 21, no. 1, pp. 33-41, 2020.

[24] B. Fan, T. Guo, R. Xu, and W. Dong, "Evolutionary game research on the impact of environmental regulation on overcapacity in coal industry," Mathematical Problems in Engineering, vol. 2021, Article ID 5558112, 19 pages, 2021.

[25] H. Kasahara, K. Shimotsu, and M. Suzuki, "Does an R \& D tax credit affect R \& D expenditure? the Japanese R \& D tax credit reform in 2003," Journal of the Japanese and International Economies, vol. 31, pp. 72-97, 2014.

[26] Q. Song and X. Wei, "An empirical study on financing constraints, premium deduction intensity and $R$ \& $D$ investment-Cbased on the data of listed companies on the growth enterprise market," Forum on China Science and Technology, vol. 11, pp. 106-115+157, 2018.

[27] W. Liu, S. Long, D. Xie, Y. Liang, and J. Wang, "How to govern the big data discriminatory pricing behavior in the platform service supply chain? an examination with a threeparty evolutionary game model," International Journal of Production Economics, vol. 231, Article ID 107910, 2021.

[28] J. L. Jiao, J. Chen, L. L. Li, and Y. F. Li, "Evolutionary game analysis of local government and corporate behavior under the carbon emission reduction reward and punishment mechanism," China Management Science, vol. 25, no. 10, pp. 140-150, 2017.

[29] G. Zhu, J. Li, Y. Zhang, and H. Liu, "Differential game analysis of the green innovation cooperation in supply chain under the background of dual-driving," Mathematical Problems in Engineering, vol. 2021, Article ID 5570285, 15 pages, 2021.

[30] B. Hall and J. V. Reenen, "How effective are fiscal incentives for R \& D? a review of the evidence," Research Policy, vol. 29, no. 4, pp. 449-469, 2000.

[31] J. Mitchell, G. Testa, M. Sanchez Martinez, P. N. Cunningham, and K. Szkuta, "Tax incentives for R \& D: supporting innovative scale-ups?” Research Evaluation, vol. 29, no. 2, pp. 121-134, 2020.

[32] D. Czarnitzki, P. Hanel, and J. M. Rosa, "Evaluating the impact of $\mathrm{R} \& \mathrm{D}$ tax credits on innovation: a microeconometric study on canadian firms," Research Policy, vol. 40, no. 2, pp. 217-229, 2011.

[33] C. J. Nie and M. L. Cheng, "Research on regional horizontal forest ecological compensation based on the theory of marginal effect: taking Beijing and ZhangCheng area of Hebei as examples," Forestry Economics, vol. 41, no. 1, pp. 24-31+40, 2019.

[34] Z. Yang, Y. Shi, and Y. Li, "Analysis of intellectual property cooperation behavior and its simulation under two types of scenarios using evolutionary game theory," Computers \& Industrial Engineering, vol. 125, pp. 739-750, 2018. 
[35] J. Hofbauer and K. Sigmund, "Evolutionary game dynamics," Bulletin of the American Mathematical Society, vol. 40, no. 4, pp. 479-519, 2003.

[36] P. R. Carlos, A. C. Jos, and S. Angel, "Evolutionary game theory: temporal and spatial effects beyond replicator dynamics," Physics of Life Reviews, vol. 6, no. 4, pp. 208-249, 2009.

[37] Z. Y. Xie, "Evolutionary game theory under bounded rationality," Journal of Shanghai University of Finance and Economics, vol. 3, no. 5, pp. 3-9, 2001.

[38] Y. Su and Y. Q. Yu, "Spatial agglomeration of new energy industries on the performance of regional pollution control through spatial econometric analysis," Science of the Total Environment, vol. 704, Article ID 135261, 2020.

[39] R. Hase and N. Shinomiya, "An evolutionary game for analyzing switching behavior of consumers in electricity retail markets," IEICE Transactions on Fundamentals of Electronics, Communications and Computer Sciences, vol. E103.A, no. 2, pp. 407-416, 2020.

[40] B. Shi, J. Zhang, Y. He, N. Ding, and Z. Qu, "Electricity consumption behavior analysis of single-phase power consumers in distribution network based on dynamic game theory," Automation of Electric Power Systems, vol. 41, no. 14, pp. 87-91, 2017.

[41] B. Li, H. Li, Q. Sun, and X. Chen, "Evolutionary game analysis between businesses and consumers under the background of Internet rumors," Concurrency and Computation: Practice and Experience, p. e5897, Wiley, Hoboken, NY, USA, 2020.

[42] C. Liu and T. Xia, "Strategy analysis of governments and new energy product manufacturers and consumers based on evolutionary game model," Soft Computing, vol. 24, no. 1, pp. 1-11, 2019.

[43] M. Feely, K. M. Raissian, W. Schneider, and L. R. Bullinger, "The social welfare policy landscape and child protective services: opportunities for and barriers to creating systems synergy," The Annals of the American Academy of Political and Social Science, vol. 692, no. 1, pp. 140-161, 2020.

[44] Z. Yang and J. Chang, "A multi-attribute decision-makingbased site selection assessment algorithm for garbage disposal plant using interval q-rung orthopair fuzzy power muirhead mean operator," Environmental Research, vol. 193, Article ID 110385, 2021. 